\title{
Algumas considerações sobre a Proteção Diplomática das Sociedades e dos seus Acionistas
}

Some considerations on the Diplomatic Protection of Corporations and their Shareholders

\section{Eduardo Pimentel de Farias}

\begin{abstract}
Using the hypothetical deductive method, we used the Barcelona Traction, Elettronica Sicula and Diallo cases to clarify the debate on the problem of diplomatic protection for corporations and their shareholders. Corporations must be seen as a being with a distinct moral personality. If the corporations and the shareholder suffered a loss, this does not imply that the two have the right to demand redress. The issue of diplomatic protection for corporations and their shareholders has been a constant theme in international jurisprudence, in the practice of States, in international conventions, in doctrine and in the course of the work of the International Law Commission on diplomatic
\end{abstract} protection. The relevance and pertinence of the topic is also recognized in the fact that diplomatic protection applies to all other legal entities constituted by the State. We share the perspective that diplomatic protection for corporations and shareholders should not be considered obsolete. This should be seen as the ultima ratio under which States can invoke the international responsibility of another State for the damage caused to a Corporation or shareholders that hold its nationality.

Keywords: diplomatic protection; corporations; shareholders; jurisprudence; practice; International Law Commission; ultima ratio. 
À semelhança das pessoas físicas, também as pessoas jurídicas ou morais podem ser vítimas de uma violação do Direito Internacional e dispor, nesta medida, da proteção diplomática do Estado da sua nacionalidade. $\bigcirc$ problema reside, contudo, na diversidade de critérios doutrinários e legislativos utilizados nos diversos ordenamentos jurídicos para a concessão da nacionalidade das pessoas morais. De fato, como não existe um direito internacional das sociedades. Logo, a qualificação do vínculo de nacionalidade das sociedades realiza-se por reenvio sistemático ao direito interno. Levanta-se, assim, a questão de saber qual seria o critério decisivo da nacionalidade das pessoas jurídicas, visto que se distingue, em parte, do regime aplicável às pessoas físicas ? Do ponto de vista doutrinário, os critérios de concessão da nacionalidade das pessoas jurídicas são geralmente classificados em três opções principais que uma vez combinados dão origem a critérios mistos. Entre os critérios principais destacamos o critério da incorporação, da sede social e do controle ? ○ critério da incorporação é o mais aceito na prática internacional e normalmente coincide com o da sede social. De resto, é este o critério adotado nos países da Common Law, nomeadamente nos Estados Unidos e no Reino Unido. No contexto da teoria da incorporação, o direito de ação através da proteção diplomática pertence ao Estado onde a sociedade foi constituída e onde se encontra formalmente registrada ${ }^{3}$. $\bigcirc$ critério da sede ou domićlio social é consagrado nos países de direito civil, apesar de não haver uma uniformidade na regra. Alguns textos descrevem o domicílio como a sede da assembleia, ao passo que outros ordenamentos mencionam a sede do conselho de administração ou o centro dos negócios da sociedade. Em termos práticos, entende-se que há uma estreita relação entre os critérios da sede social e da incorporação, que faz com que coincidam frequentemente ${ }^{4}$.

Finalmente, a noção do controle surge no direito angloamericano na forma de lex specialis para a determinação do carácter inimigo das sociedades em tempos de guerra. Com efeito, uma sociedade comercial pode estar vinculada a um Estado por critérios essencialmente formais /constituição e sede sociall, mas receber ordens e instruções de pessoas residentes em países inimigos. Assim, a legislação sobre bens inimigos é tida como um instrumento de guerra econômica na medida em que visa privar o adversário dos benefícios do anonimato e da personalidade distinta das sociedades. Este mecanismo corresponde a uma verdadeira arma de proteção e defesa para 0 Estado beligerante ${ }^{5}$. No contexto dos períodos de paz, todavia, alguns autores consideram a noção de controle real como critério para determinação da nacionalidade das pessoas jurídicas. De acordo com este critério, a sociedade teria a nacionalidade do grupo majoritário dos seus acionistas. $\bigcirc$ controle, porém, é uma noção complexa e dificilmente apreendida pelo Direito. Além disso, para aplicar essa teoria à matéria da nacionalidade das pessoas jurídicas, o legislador teria

\footnotetext{
${ }^{1}$ Cf. Dominique Carreau, "Droit International",438; Makarov, Alexander, "Consideraciones sobre el Derecho de Protección Diplomática", 528.

${ }^{2}$ Segundo J. Dugard, os critérios de concessão da nacionalidade das pessoas jurídicas podem ser classificados em até sete opções principais. Ver: "Quatrième Rapport sur la Protection Diplomatique", 13.

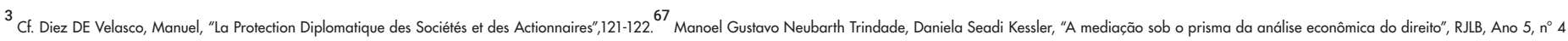
(2019), p. 537-538.

${ }^{4}$ O artigo 33 do Código Civil português retrata a sede social como a sede principal e efetiva da administração da pessoa coletiva. Dugard, J. "Quatrième Rapport sur la Protection Diplomatique",15.

5 O'Connell, D.P. "International Law",1127; VIssicher, Ch. "La Nationalité et le Caractére Ennemi des Sociétés Commerciales",511-512.
} 
que renunciar ou fixar, de maneira arbitrária e geral, todos os elementos determinantes do controle. Nesta medida, a jurisprudência posterior à Segunda Grande Guerra acaba por abandonar esse critério em favor das noções mais tradicionais ${ }^{6}$.

Esta questão foi, inclusive, abordada pela Corte Internacional de Justiça (CII) no caso Barcelona Traction, que opôs a Espanha à Bélgica. Segundo a narrativa dos fatos, a sociedade Barcelona Traction era uma holding sediada em Toronto (Canadá) com atividades ligadas à produção e distribuição de energia elétrica na província espanhola da Catalunha. No período imediato do pós-guerra, as autoridades espanholas recusaram a autorização de transferências em moeda estrangeira para o pagamento de juros de obrigações emitidas pela Barcelona Traction. Na sequência deste acontecimento, três espanhóis detentores de obrigações recentemente adquiridas instauraram processos de falência contra esta sociedade. No ano de 1948, os tribunais espanhóis declararam a falência da sociedade e das suas subsidiárias na Espanha. Na ausência de medidas diretas por parte do governo canadense, a Bélgica decidiu submeter o caso à Cll, reclamando a reparação dos prejuízos causados aos acionistas belgas da Barcelona Traction. A tese belga sustentava que os processos de falência nos tribunais espanhóis teriam sido forjados com o intuito de transferir o controle das subsidiárias da Barcelona
Traction para a Espanha. Estimava-se que 88\% do capital social da sociedade era detido por nacionais belgas ? Tribunal reprovou, contudo, o critério do controle em matéria de nacionalidade das pessoas jurídicas e declarou a ilegitimidade da Bélgica para exercer a proteção diplomática de uma sociedade canadense. Em termos gerais, a ClJ confirma os critérios da incorporação e da sede social por meio de numerosos instrumentos internacionais na medida em que atribui o direito de exercer a proteção diplomática ao Estado sob cujas leis a sociedade se constituiu e em cujo território tem a sua sede. Por outro lado, a Corte adverte que, apesar da prática de alguns Estados condicionarem o direito da proteção diplomática à existência de outros vínculos adicionais mais estreitos e preponderantes, nenhum critério absoluto deve ser aceito. Na verdade, tanto a analogia com o caso Nottebohm como a aplicação do princípio da "conexão genuína" no campo concreto da proteção diplomática das pessoas jurídicas foram rejeitadas pelo Tribunal no julgamento do caso Barcelona Traction ${ }^{8}$. De fato, nessa decisão, a ClJ não tratou da situação particular de uma sociedade que, apesar de constituída num Estado, detém um vínculo mais estreito e permanente com outro Estado. Entre a sociedade Barcelona Traction e o Canadá existiam múltiplos vínculos mantidos desde a sua constituição até àquela data. Destaca-se, ainda, que a

\footnotetext{
${ }^{6}$ Ver Borchard, Edwin M. "Protection Diplomatique des Nationaux à l'Érranger",296-297; VISSICHER, P. "La Protection Diplomatique des Personnes Morales", 444-445.

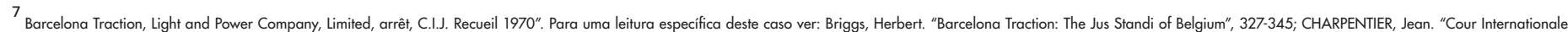

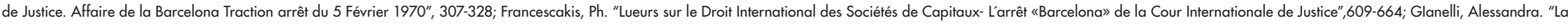

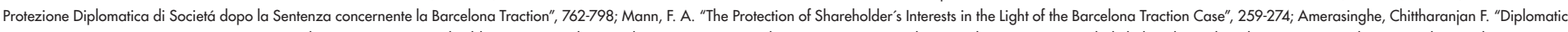

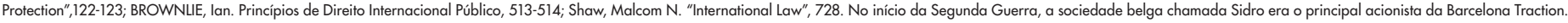

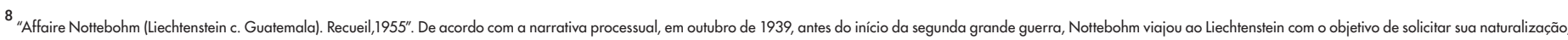

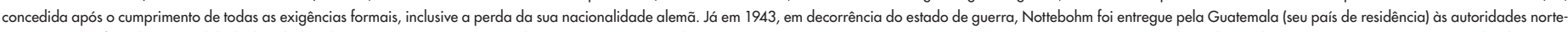

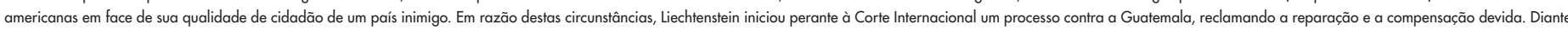

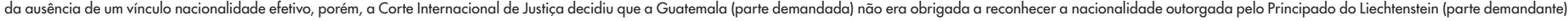

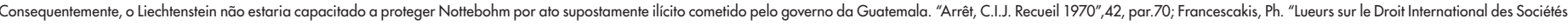
de Capitaux- L'arrêt «Barcelona» de la Cour Internationale de Justice", 645.
} 
sociedade conservava no Canadá a sua sede estatutária, a compatibilidade e registro dos seus acionistas, bem como a reunião do seu conselho de administração ${ }^{9}$. O princípio geral do caso Barcelona Traction foi acolhido no projeto de artigo $9^{\circ}$ da Comissão de Direito Internacional (CDI) sobre a proteção diplomática com uma exceção. Será considerado como estado de nacionalidade, com direito ao exercício da proteção diplomática, aquele estado que a sociedade tenha um vínculo mais estreito e permanente, embora não seja o da sua constituição. Para a Comissão, pareceu errado conferir exclusivamente o direito de exercício da proteção diplomática ao Estado cujo vínculo com a sociedade era mais tênue. Por outro lado, a prática internacional indica que esse Estado raramente estaria disposto a proteger tal sociedade. É necessário destacar, contudo, que $\circ$ projeto de artigo $9^{\circ}$ da CDI não autoriza ações múltiplas. Além disso, o Estado com vínculo mais estreito e permanente com uma sociedade só poderá ser considerado como seu Estado de nacionalidade, para fins da proteção diplomática, se três condições estiverem cumulativamente reunidas: 1) que a sociedade seja controlada por nacionais estrangeiros; 2) que ela não exerça atividades relevantes no país da sua constituição; 3) que tenha a sede da administração e do seu controle financeiro em outro Estado. Caso a sede real da sociedade e o lugar do seu controle financeiro se situem em Estados diferentes, - Estado onde a sociedade foi constituída permanece como único Estado habilitado para exercer sua proteção ${ }^{10}$. No que se refere à continuação da nacionalidade de uma sociedade, o parágrafo 1 do projeto de artigo $10^{\circ}$ da CDI reafirma o princípio geral descrito no projeto de artigo $5^{\circ}$ para as pessoas físicas. Assim, um Estado só terá o direito de exercer a sua proteção diplomática em benefício de uma sociedade se esta detiver a sua nacionalidade ou a nacionalidade de um Estado antecessor (na hipótese da sucessão de Estados), tanto no momento do prejuízo quanto na apresentação oficial da reclamação. Uma exceção ao princípio da continuação da nacionalidade está, entretanto, prevista no parágrafo $2^{\circ}$ do projeto de artigo $10^{\circ}$ para cobrir a hipótese em que o Estado perde o direito de exercer a sua proteção diplomática, caso a sociedade adquira a nacionalidade do Estado contra o qual a reclamação foi feita. ${ }^{11}$

Ainda resta mencionar, que na sucessão de Estados, uma sociedade muda de nacionalidade sem precisar mudar de personalidade jurídica. Em termos práticos, porém, a mudança de nacionalidade de uma sociedade é pouco frequente, apesar das inúmeras vantagens dessa solução se comparada com todo o trabalho que implica a dissolução da entidade e sua recriação num outro país. ${ }^{12}$ Entende-se, todavia, que um Estado deveria poder assumir a proteção de seus nacionais acionistas de uma sociedade vítima de violação de Direito Internacional. Esta tese também foi levantada pela Cll no julgamento do caso Barcelona Traction, apesar da Bélgica indicar claramente que não fundava sua demanda na violação direta ao direito dos acionistas. ${ }^{13}$ Segundo DIEZ DE VELASCO, um estudo superficial da prática

\footnotetext{
9 "Arrêt, C.I.J. Recueil 1970", 42,par.71.

10 "Projet d'Articles sur la Protection Diplomatique et Commentaires y Relatifs (2006)", 55-56.

${ }^{11}$ Idem, $57-58$.

12 Eric Wyler, "La Régle dite de la Continuité de la Nationalité dans le Contentieux International", 104-105.

13 "Arrêt, C.I.J. Recueil 1970", 48, par.92-93.
} 
diplomática e da jurisprudência arbitral poderia induzir que o Direito Internacional admite a proteção diplomática dos acionistas de uma sociedade estrangeira. Um estudo mais aprofundado, porém, revela que as indenizações em benefício de acionistas são geralmente obtidas pelos Estados vencedores de uma guerra nos tratados de paz ou nos tratados de indenização global em caso de nacionalização ${ }^{14}$. Forçar, deste modo, analogias ou conclusões decorrentes da prática diplomática, ou da jurisprudência arbitral, é ignorar a natureza particular de lex sepecialis do tema, conduzindo, consequentemente, a erros. Uma sociedade deve ser vista como um ser corporativo de personalidade moral distinta. Assim, se a sociedade e o acionista sofreram um prejuízo, isto não implica que os dois tenham o direito de exigir uma reparação. Efetivamente, se a pessoa moral sofrer um dano, os acionistas são afetados nos seus interesses, mas não propriamente em seus direitos ${ }^{15}$. A distinção entre os direitos da sociedade e do acionista fundamenta-se nas regras geralmente acolhidas pelos diversos sistemas de direito interno. Como a sociedade comercial é uma instituição criada pelos Estados no domínio reservado da sua competência, o Direito Internacional recorre às regras pertinentes do direito interno, sempre que surjam questões jurídicas relativas ao tratamento das sociedades e dos seus acionistas. ${ }^{16}$ Cumpre, todavia, mencionar que, em matéria de sociedades, qualquer fórmula unitária é tida como ilusória. As legislações dos Estados reconhecem diversos tipos de sociedades agrupadas pela doutrina em duas categorias essenciais: as sociedades de pessoas e as sociedades de capitais ou anônimas. Para a ClJ, o que diferencia esses dois tipos de sociedades é a coesão da personalidade jurídica nas sociedades de capitais e a autonomia conservada pelos membros das sociedades de pessoas. No caso das sociedades de capitais, a situação jurídica de sócio independe das suas atribuições pessoais. Nas sociedades de pessoas, a qualidade de sócio é intransferível sem o consentimento dos outros sócios. Neste sentido, o direito de ação através da proteção diplomática é reconhecido ao Estado de nacionalidade dos sócios de uma sociedade de pessoas, mesmo que o objeto do prejuízo seja o patrimônio social, pois o associado será a pessoa imediatamente lesada. Já no caso das sociedades de capitais, esta regra não tem o mesmo efeito. Neste tipo de sociedade, o problema consiste na determinação da nacionalidade da sociedade, tendo em conta que os sócios se beneficiam de uma responsabilidade limitada correspondente apenas ao capital aportado por eles ${ }^{17}$.

Apesar disso, a Cll reconhece que a proteção pelo Estado de nacionalidade desse último acionista deve ser admitida em duas hipóteses: 1) nos casos em que a sociedade tenha deixado de existir; 2) quando o acionista tenha sido lesado nos seus direitos próprios enquanto sócio e independentemente dos danos sofridos pela sociedade. Na primeira hipótese, o Tribunal reconhece o direito de ação do Estado de nacionalidade dos acionistas quando a sociedade de capital em questão deixa de existir. Nesta medida, o desaparecimento em direito da

\footnotetext{
14 "Arrêt, C.I.J. Recueil 1970",35-40, par.44 e 62; RIVER, Rafhaële. Lagrange, Philippe. "Travaux de la Commission du Droit International (cinquante-huitième session) et de la Sixième Commission (soixante et unième session)",334.

15 "Arrêt, C.I.J. Recueil 1970", 33 e 37, par.38 e 50.

16 "Arrêt, C.I.J. Recueil 1970",34, par. 40; Diez DE Velasco, Manuel. "La Protection Diplomatique des Sociétés et des Actionnaires",112-120. "13 "Diez De Velasco, "Instituciones de Derecho Internacional Público",748.

17 "Arrêt, C.I.J. Recueil 1970", 36-41, par.47, 64 e 66.
} 
sociedade priva os seus acionistas do dever de recorrer ao Estado de nacionalidade da sociedade. Para a Corte, porém, um direito de ação independente só é possível quando todas as possibilidades de mediação pela sociedade forem esgotadas. Na segunda hipótese, afigura-se a possibilidade dos acionistas serem as vítimas diretas do ilícito internacional. Neste caso, como $\circ$ Estado de nacionalidade da sociedade não tem qualidade para agir em seu favor, autoriza-se a proteção diplomática dos acionistas pelo Estado de sua nacionalidade. Entre os direitos genericamente reconhecidos pela ordem interna aos acionistas, destacam-se: o direito ao voto, ao dividendo declarado, de participação nas assembleias gerais e à parte dos ativos residuais da sociedade em liquidação. ${ }^{18}$

Cumpre ainda mencionar, que as opiniões individuais dos juízes FITZMAURICE, TANAKA e JESSUP defendiam, no caso Barcelona Traction, que o princípio da proteção diplomática dos acionistas também poderia ser aplicado na hipótese em que a sociedade prejudicada tenha a mesma nacionalidade do Estado reclamado. $\bigcirc$ Tribunal observou, porém, que essa teoria jamais poderia ser aplicada ao caso, visto que a Espanha não era o Estado de nacionalidade da sociedade. Com efeito, é no contexto da interpretação dos tratados que essa tendência se confirma, como se verifica no emblemático caso Elettronica Sicula. ${ }^{19}$ Neste caso, a sociedade americana Raytheon aumentou progressivamente seu investimento na sociedade italiana de componentes eletrônicos Elettronica Sicula S.p.A. (ELSI) até chegar ao controle de $99,16 \%$ do seu capital no ano de 1967. Os restantes 0,84\% pertenciam à sociedade americana Machlett. Em virtude da péssima situação técnica e econômica da sociedade ELSI, a Reytheon e a Machlett decidiram proceder a sua liquidação. No ano de 1968, a fábrica foi fechada e os trabalhadores da sociedade receberam cartas de licença. No entanto, autoridades italianas interpuseram uma ordem de requisição da sociedade e dos bens conexos da ELSI por um período de seis meses, sob o argumento de geral interesse público econômico. Neste mesmo ano, diante da impossibilidade de cumprir os vencimentos das suas obrigações, a ELSI pediu falência. Por sua vez, os Estados Unidos apresentaram uma reclamação contra a Itália, alegando que a requisição ilegal conduziu não só à falência da ELSI, mas também a violação de um certo números de direitos reconhecidos aos seus acionistas nos tratados de amizade, comércio e navegação, celebrados entre os dois países em 1948 e de um acordo complementar em 1951. Finalmente, em 1989, a ClJ admitiu a legitimidade ativa dos Estados Unidos para apresentar a demanda contra a Itália por prejuízos causados à sociedade ELSI, apesar de não assinalar expressamente o fundamento jus standi americano. Este silêncio, contudo, pode ser explicado pelo fato da Corte não se ter dedicado à avaliação do Direito Internacional costumeiro, mas à interpretação dos textos convencionais de 1948 e de 1951, que previam a proteção de acionistas americanos no estrangeiro ${ }^{20}$. A questão da proteção diplomática dos acionistas foi um tema constante não somente na jurisprudência internacional, mas

\footnotetext{
18 "Arrêt, C.I.J. Recueil 1970", 36-41, par.47, 64 e 66.

19 Idem, 48, 72-74,134 e 191-193; "Arrêt, C.I.J. Recueil 1989."

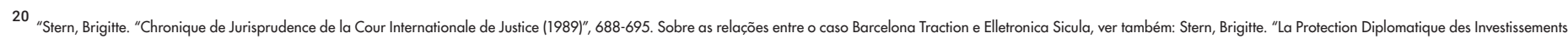
Internationaux- De Barcelona Traction à Eleftronica Sicula ou les glissements progressifs de l'analyse", 897-945.
} 
também na prática dos Estados, nas convenções internacionais, na doutrina e, sobretudo, no curso dos trabalhos da CDI relativos à codificação da proteção diplomática. Neste último, a solução proposta passa por um equilíbrio entre a proteção legítima dos acionistas e a manutenção do regime clássico da proteção diplomática. Assim, para a Comissão, a exceção da proteção diplomática pelos Estados de nacionalidade dos acionistas deve estar subordinada a condições que impeçam o surgimento de reclamações excessivas e abusivas, causadoras de desordem e ingerência nas relações econômicas internacionais. ${ }^{21}$ Segundo a alínea al do projeto de artigo $11^{\circ}$ da CDI, o Estado de nacionalidade dos acionistas está habilitado a intervir em seu favor quando a sociedade tenha deixado de existir no lugar da sua constituição por um motivo sem relação com o prejuízo. Como sabemos, uma sociedade nasce no Estado que the reconhece a personalidade jurídica. Consequentemente, o direito de dizer se uma sociedade deixou de existir pertence também ao Estado que concedeu a sua existência. No julgamento do caso Barcelona Traction, a Corte não diz expressamente que a sociedade deveria ter deixado de existir no lugar da sua constituição jurídica, de modo a que os acionistas tivessem o direito de intervir. Apesar disto, fica subentendido, no contexto desse julgamento, que a sociedade deveria ter deixado de existir no seu Estado de constituição e não no Estado em que sofreu o prejuízo. ${ }^{22}$ A expressão "por um motivo sem relação com o prejuízo" destina-se a limitar as circunstâncias em que o Estado de nacionalidade dos acionistas poderá intervir em decorrência de um prejuízo causado à sociedade. Assim, só se pode falar em proteção diplomática pelo Estado de nacionalidade dos acionistas no caso em que estes tenham sido lesados por danos sem qualquer relação com o prejuízo que levou ao desaparecimento da sociedade. Nesses termos, a alínea a) do projeto de artigo $11^{\circ}$ deve ser lida conjuntamente com - parágrafo 3 do projeto de artigo $10^{\circ}$ da CDI. Este último estabelece que, se o prejuízo leva ao desaparecimento da sociedade, o direito de exercer a sua proteção pertence ao Estado de nacionalidade da sociedade. $\bigcirc$ Estado reclamante deve, portanto, provar se a reclamação é ou não apresentada em face do mesmo prejuízo que levou ao fim da sociedade. ${ }^{23}$ Na alínea b) do projeto de artigo $11^{\circ}$, a CDI limita o exercício da proteção diplomática pelo Estado de nacionalidade dos acionistas a outras duas condições restritivas: 1) que a sociedade tenha, à data do prejuízo, a nacionalidade do Estado responsável pelo dano; 2) que a constituição da sociedade nesse Estado tenha sido uma exigência para que a mesma pudesse exercer as suas atividades. É necessário notar, todavia, que essas duas condições não são alternativas. A Comissão antecipa-se, contudo, para reportar que não é necessário que o direito formal do Estado obrigue a constituição da sociedade no país. $\bigcirc$ desenvolvimento progressivo do Direito Internacional tem, com efeito, atestado inúmeros casos em que a exigência de constituição da sociedade num determinado Estado se dá através da pressão informal ou política sob os interesses estrangeiros. ${ }^{24}$ Recentemente, no julgamento do caso Diallo, a ClJ encontrou a ocasião para completar e clarificar a alínea b) do projeto

\footnotetext{
21 Cf. Mahiou, Ahmed. "Le Droit International ou La Dialectique de La Rigueur et de La Flexibilité- Cours général de droit international public",449-450.

22 "Projet d'Articles sur la Protection Diplomatique et Commentaires y Relatifs (2006)", 62-63; Diez DE Velasco, Manuel. "La Protection Diplomatique des Sociétés et des Actionnaires", 111.

23 "Projet d'Articles sur la Protection Diplomatique et Commentaires y Relatifs (2006)",59-63.

24

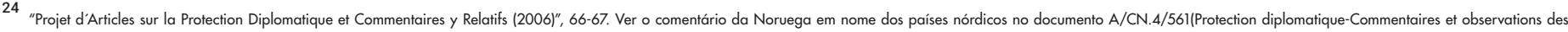
gouvernements), 35 .
} 
de artigo $11^{\circ}$, referindo-se à exceção como uma espécie de proteção diplomática por substituição. Para a Corte, a teoria da proteção por substituição visa oferecer uma proteção em último recurso aos acionistas estrangeiros que não puderam invocar o benefício de um acordo internacional ou de qualquer outro recurso por atos ilícitos cometidos contra a sociedade pelo seu Estado de nacionalidade. ${ }^{25}$ O caso Diallo trata da reclamação de um cidadão guineense contra o comportamento das autoridades da República Democrática do Congo, que teriam causado prejuízo a ele e às suas empresas constituídas nesse país. Com base no exame dos fatos, a Corte concluiu que as sociedades em questão foram criadas naturalmente e inscritas no registro de comércio da cidade de Kinshasa. Contudo, não ficou suficientemente comprovado pelo Tribunal que a nacionalidade congolesa das sociedades tivesse sido exigida aos seus fundadores para que a mesma fosse habilitada a operar nos setores econômicos. Assim, apesar de admitir a teoria de uma proteção diplomática por substituição, a Corte considerou que ela não se aplicava ao caso por entender que a segunda condição da alínea b) do projeto de artigo $11^{\circ}$ não teria sido satisfeita. Neste caso, enquanto a nacionalidade congolesa das sociedades era um fato tido como incontroverso (primeira condição), estimou-se que essa mesma nacionalidade teria sido resultado da livre escolha do seu proprietário e não de uma exigência do direito local (segunda condição). ${ }^{26}$ No projeto de artigo $12^{\circ}$, a CDI também reconhece o direito dos acionistas de serem protegidos pelos seus Estados de nacionalidade contra a violação direta dos seus próprios direitos. A Comissão não precisa, porém, o sistema jurídico adequado para determinar quais são os direitos próprios dos acionistas em oposição aos direitos da sociedade. No caso Barcelona Traction, a Corte menciona alguns dos direitos mais evidentes dos acionistas, indicando, todavia, que essa listagem não é exaustiva. Na maioria dos casos, essa questão é definida pelo direito interno do Estado de nacionalidade da sociedade. Cabe, assim, ao tribunal invocar os princípios gerais do direito interno desse Estado para que os acionistas estrangeiros não sejam objeto de um tratamento discriminatório. ${ }^{27}$ Além das sociedades, sabemos que o Estado cria pelo seu direito interno outros tipos de pessoas jurídicas, como as empresas públicas, universidades, escolas, fundações, igrejas, coletividades locais, associações sem fins lucrativos, organizações não governamentais e parcerias. $\bigcirc$ exame das pessoas jurídicas no contexto do direito internacional costuma limitar-se, contudo, às sociedades sob o argumento de que não é possível empregar aos outros tipos de pessoas morais características comuns e uniformes. Com base nesse pressuposto, o projeto de artigo $13^{\circ} \mathrm{da} C D I$ prevê que os princípios anunciados ao Estado de nacionalidade das sociedades também se apliquem à proteção diplomática de outras pessoas jurídicas constituídas pelo Estado. Reclama-se, portanto, às autoridades e demais órgãos jurisdicionais competentes que examinem a natureza e as funções da pessoa jurídica em causa, para

\footnotetext{
25 "Ahmadou Sadio Diallo (Republique de Guinée c. Republique Démocratique du Congo) Exceptions Préliminaires, CIJ, Recueil 2007",37, par. 88.

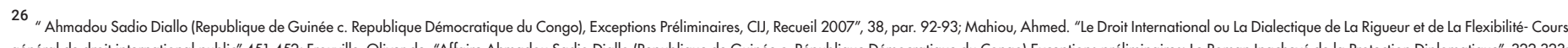

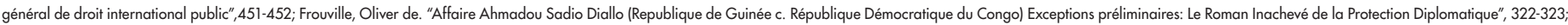
Dorigo, Stefano. "Sulla Protezione Diplomática Degli Azionisti: II Caso Diallo di fronte alla Corte Internazionale di Giustizia", $729-734$. 
decidir sobre a aplicação ou não das disposições relativas à proteção diplomátic das sociedades. Deve-se recordar, todavia, que a proteção diplomática é um procedimento reservado a pessoas físicas ou jurídicas que não façam parte do aparelho do Estado. Assim, tanto uma entidade da administração local como uma universidade financiada ou controlada pelo Estado não terão as condições exigidas para dispor desta proteção. ${ }^{28}$ A proteção diplomática das sociedades e dos seus acionistas foi objeto de diversas decisões judiciais, porém, o julgamento do caso Barcelona Traction domina todos os debates, tendo sido tema de uma série de estudos críticos e monográficos. Inclusive, no âmbito da própria CDI, o relator J. DUGARD destaca a sua importância para reflexão das diferentes regras que regem a proteção diplomática das sociedades. Com efeito, não se poderia formular uma regra sobre a questão da proteção diplomática da sociedade e dos seus acionistas sem pretender examinar as repercussões desse julgado paradigmático. ${ }^{29}$ Alguns autores observam, entretanto, que as disposições relativas à proteção diplomática das sociedades aprovadas no projeto de artigos de 2006 permanecem ditadas por considerações dogmáticas e políticas. Para essa doutrina, as disposições em causa ainda têm uma formulação pouco consensual, complexa e relativamente aberta. Nesse sentido, JULIANE KOKOTT acrescenta que a análise dos tratados de investimento demonstra que a proteção diplomática não mas desempenha um papel decisivo na resolução de diferendos envolvendo sociedades e acionistas. E que os atuais acordos dão preferência a procedimentos alternativos para resolução do litígio, permitindo que os investidores tenham acesso às instâncias de arbitragem internacional. Para a autora, no contexto do investimento estrangeiro, o direito tradicional da proteção diplomática teria sido largamente substituído por um número de procedimentos para resolução de litígios baseados em tratados de investimento. ${ }^{30}$ No sentido inverso, partilhamos a perspectiva de que a proteção diplomática das sociedades e dos acionistas está longe de ser considerada como obsoleta. Aliás, esta deve ser tida como ultima ratio sob o qual os Estados poderão invocar a responsabilidade internacional de outro Estado pelo prejuizo causado a uma sociedade ou acionistas que detenham a sua nacionalidade. Nada impede, porém, que se fale em atualização do instituto ou mesmo numa interpretação mais adaptada ao direito internacional e as suas evoluções em matéria econômica.

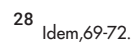

29 J. Dugard, "Quatrième Rapport sur la Protection Diplomatique", 2.

30

Juliane Kokott, "Interim Report on 'The Role of Diplomatic Portection in the Field of the Protection of Foreign Investment", 31. Ver também: David Bederman, "Interim Report on "Lump Sum Agreements and Diplomatic Protection", 3-20.
} 
ULPLR I ULP LAW REVIEW I REVISTA DE DIREITO DA ULP

VOL.15 I №1

DOI: $10.46294 /$ ulplr - rdulp.v15i 1.7941

\section{Referências}

AHMADOU SADIO DIALLO (République de Guinée c. République démocratique du Congo). Exceptions préliminaires, CIJ Recueil 2007. Julgamento de 24.05.2007. https://www.icj-cii.org/fr/affaire/103

AMERASINGHE, CHITTHARANJAN F. Diplomatic Protection. Oxford: Oxford University Press, 2008.

BARCELONA TRACTION, Light and Power Company, Limited. Arrêt, CIJ, Recueil 1970. Julgamento de 5.02.1970. https://www. ici-cii.org/public/files/case-related/50/050-19700205-JUD-01-00-EN.pdf

BADERMAN, DAVID. "Interim Report on "Lump Sum Agreements and Diplomatic Protection". International Law Association- New Delhi Conference- Committee on Diplomatic Protection of Persons and Property (2002): 3-20. https://www.ila-hq.org/index.php/ committees

BORCHARD, EDWIN M. "Protection Diplomatique des Nationaux à L’Etranger".

BRIGGS, HERBERT. "Barcelona Traction: The Jus Standi of Belgium". American Journal of International Law 65, no. 2 labril de 1971): 327-345.

BROWNLIE, IAN. Princípios de Direito Internacional Público. Traduzido por Maria Manuela Farrajota et al. Lisboa: Fundação Calouste Gulbenkian, 1997.

CARREAU, DOMINIQUE. Droit International. Paris: Pedone, 1994.

CHARPENTIER, JEAN. "Cour Internationale de Justice. Affaire de la Barcelona Traction Arrêt du 5 Février 1970". Annuaire Français de Droit International 16, (1970):307-328.

Código Civil Português. Decreto-Lei n. 47344. Diário do Governo n. 274/1966, Série I de 1966-11-25. https://dre.pt/web/ guest/pesquisa/-/search/477358/details/normal?|l=1

DIEZ DE VELASCO, MANUEL. Instituciones de Derecho Internacional Público. Madrid: Tecnos, 1999.

DIEZ DE VELASCO, MANUEL. "La Protection Diplomatique des Sociétés et des Actionnaires".Collected Courses of the Hague Academy of International Law 141, no 1, (1974):87-185.

DORIGO, STEFANO. "Sulla Protezione Diplomática Degli Azionisti: ॥l Caso Diallo di fronte alla Corte Internazionale di Giustizia". Rivista di Diritto Internazionale 90, no 3, (2007):705-737.

DUGARD, JOHN R. QUATRIÈME rapport sur la protection diplomatique. Doc. A/CN.4/530, (2003). https://legal.un.org/ilc/ documentation/french/a_cn4_530.pdf

ELETTRONICA SICULA. Estados Unidos da América c. Itália. Arrêt, CIJ, Recueil 1989 Julgamento de 20.07.1989. https://www. icj-cii.org/public/files/case-related/76/076-19890720-JUD-01-00-EN.pdf

FRANCESCAKIS, PH. "Lueurs sur le Droit International des Sociétés de Capitaux- L'arrêt «Barcelona» de la Cour Internationale de Justice". Recueil des Cours de Droit International Public (1970): 609-664.

FROUVILLE, OlIVER DE. "AFFAIRE AHMADOU SADIO DIALLO (Republique de Guinée c. République Démocratique du Congo) Exceptions préliminaires: Le Roman Inachevé de la Protection Diplomatique". Annuaire Français de Droit International 53, (2007): 291-327. 
ULPLR I ULP LAW REVIEW I REVISTA DE DIREITO DA ULP

VOL.15 I №1

DOI: $10.46294 /$ ulplr - rdulp.v15i1.7941

GIANELLl, ALESSANDRA. "La Protezione Diplomatica di Societá dopo la Sentenza Concernente la Barcelona Traction". Rivista di Diritto Internazionale, (1986): 762-798.

KOKOTT, JULIANE. "Interim Report on "The Role of Diplomatic Portection in the Field of the Protection of Foreign Investment". International Law Association- New Delhi Conference - Committee on Diplomatic Protection of Persons and Property(2002): 21-31. https://www.la-hq.org/index.php/committees

MAHIOU, AHMED. Le Droit International ou La Dialectique de La Rigueur et de La Flexibilité- Cours général de droit international public. Collected Courses of the Hague Academy of International Law 337. Leiden; Boston: M. Nijhoff, 2009.

MAKAROV, ALEXANDER. "Consideraciones sobre el Derecho de Protección Diplomática". Revista Española de Derecho Internacional 8, no 1-2-3, (1955):511-552.

MANN, F. A. "The Protection of Shareholder's Interests in the Light of the Barcelona Traction Case". The American Journal of International Law 67, no. 2 (abril de 1973): 25-67.

NOTTEBOHM. LIENCHTENSTEIN C. GUATEMALA. CIJ. Recueil, 1955. Julgamento de 6.04.1955. https://hmjo.tripod.com/ Dip/Cases/Nottebohm.htm

O'Connell, D.P. International Law. Londres: Stevens and Sons Limited, Vol 2, 1965.

Projet d'Articles sur la Protection Diplomatique et Commentaires y Relatifs. Doc. A/61/10, (2006). Comentários e Observações recebidos de Governos. Doc. A/CN.4/561- 27 de janeiro de 2006. Doc. A/CN.4/561/Add.1- 3 de abril de 2006. https:// legal.un.org/ilc/texts/instruments/french/draft_articles/9_8_2006.pdf

Propriétés Religieuses (France, Royaume-Uni, Espagne c. Portugal). Recueil des Sentences Arbitrales, Vol.I. de 4.9.1920. https:// legal.un.org/riaa/cases/vol_I/7-57.pdf

RIVER, RAFHAËLE. LAGRANGE, PHILIPPE. "Travaux de la Commission du Droit International (cinquante-huitième session) et de la Sixième Commission (soixante et unième session)". Annuaire Français de Droit International 52, (2006): 305-350

SHAW, M.N. International Law. Cambridge: Cambridge Universty Press, 5 ed. 2003.

STERN, BRIGITTE. "Chronique de Jurisprudence de la Cour Internationale de Justice (1989)". Journal du droit international, no 3,(1990):688-695.

STERN, BRIGITTE. "La Protection Diplomatique des Investissements Internationaux- De Barcelona Traction à Elettronica Sicula ou les Glissements Progressifs de l'analyse". Journal du droit international 117, no 4, (outubro à dezembro de 1990):897-945.

STRUNSKY-MERGÉ. Comissão de Conciliação Estados Unidos-ltália. Decisão no 55 de 10.06.1955. https://legal.un.org/riaa/ cases/vol_XIV/236-248.pdf

VISSCHER, CHARLES de. "La Nationalité et le Caractére Ennemi des Sociétés Commerciales". Revue De Droit International Privé et de Droit Pénal International 13, (1917): 501-511

VISSCHER, PAUL. "La Protection Diplomatique des Personnes Morales". Recueil des Cours de I'Academie de Droit International de LA HAYE 102, no 1, (1961): 395-513.

WYLER, ERIC. La Régle dite de la Continuité de la Nationalité dans le Contentieux International. Paris: Press Universitaires de France, 1990. 